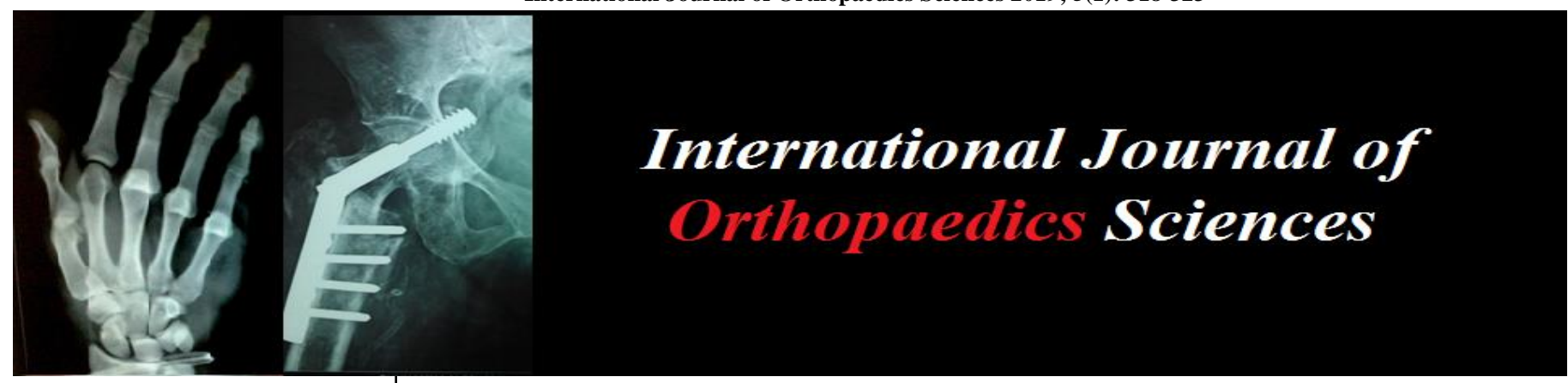

ISSN: $2395-1958$

IJOS 2019; 5(1): 318-323

(C) 2019 IJOS

www.orthopaper.com

Received: 14-11-2018

Accepted: 18-12-2018

Dr. Abhimanyu Singh

Junior Resident, Department of Orthopaedics, Sri Devaraj Urs

Medical College, Kolar,

Karnataka, India

Dr. Nagakumar JS

Additional Professor,

Department of Orthopaedics, Sri

Devaraj Urs Medical College,

Kolar, Karnataka, India

Correspondence

Dr. Nagakumar JS

Additional Professor,

Department of Orthopaedics, Sri

Devaraj Urs Medical College,

Kolar, Karnataka, India

\section{A study on the functional outcome of fracture neck of femur managed with cannulated cancellous screws}

\author{
Dr. Abhimanyu Singh and Dr. Nagakumar JS
}

DOI: https://doi.org/10.22271/ortho.2019.v5.i1f.57

\section{Abstract}

Background: Hip fractures are common, they comprise about $20 \%$ of orthopedic trauma. Femoral neck fractures almost account for $50 \%$ of all the fractures around hip. Fracture neck of femur still are unsolved fractures. It is a fracture of fragility due to osteoporosis in elderly, in younger age group, it results from a high-energy trauma sustained commonly in a road traffic accident.

Aims and Objective: To study the functional outcome in patients treated with cannulated cancellous screws for neck of femur fracture.

Materials and Methods: In this prospective study, 30 patients with neck of femur fractures were treated with cannulated cancellous screws at R.L. Jalappa Hospital, Kolar during a period of September 2016 to September 2018. Patients with pathological fractures, osteoarthritis of hip and pediatric patients were excluded from the study. Patients were followed up for a period of 6 months and functionally assessed using Modified Harris Hip score.

Results: 21 were males \& 9 females with mean age of 41.3 years. RTA was cause of injury in most patients. Mean duration of union was 15 weeks. Most of patients had slight to no pain, most of the patients could perform their daily activities without any restriction and all patients had good range of motion without any deformity.

Conclusion: At the end of the study we conclude that cannulated cancellous screws provide adequate fracture fixation, stability, strength, early mobility and excellent union rate of neck of femur fractures.

Keywords: Fracture neck of femur, cannulated cancellous (cc) screws, osteosynthesis

\section{Introduction}

Hip fractures are common, they comprise about $20 \%$ of the operative workload of orthopedic trauma. Femoral neck fractures almost account for 50\% of all the fractures around hip. Lifetime risk of sustaining hip fracture is high and lies within a range of $40 \%$ to $50 \%$ in females and $14 \%$ to $22 \%$ in males. Life expectancy is increasing throughout the world, and the demographic changes is causing the hip fractures incidence to increase ${ }^{[1]}$.

Fracture neck of femur have always been a great challenge to surgeons and still are unsolved fractures. It is often a fracture of fragility due to osteoporosis in elderly, though in younger age group, it usually results from a high-energy trauma sustained commonly in a road traffic accident ${ }^{[2]}$.

Regardless of age of the patient, or the fracture pattern, the primary goal of management of the fracture is to bring the patient back to a pre-fracture level of function. The ideal treatment of intra-capsular fractures of the femur neck is still anatomic reduction followed by stable bone fixation.

For displaced femoral neck fractures, reduction, compression, and rigid internal fixation is required if union is to be predictable. As nonunion and osteonecrosis develop frequently after internal fixation of displaced fractures of femur neck, many surgeons recommend primary prosthetic replacement as the treatment of choice in elderly ambulatory patients ${ }^{[3,4]}$.

Internal fixation remains the treatment of choice for these fractures in all age groups, more so in displaced fractures in the younger patients, where preservation of femoral head is the priority. However, the optimal timing for surgical fixation of these fractures is still open to debate. It is advocated that fracture reduction and fixation should be performed as a surgical emergency in an attempt to restore the precarious blood supply to the femoral head and 
prevent complications such as non-union and avascular necrosis, the incidence of these complications being 10-20\% and 10-30\% respectively. Avascular necrosis and non-union predisposes to future degenerative arthritis of hip joint involved ${ }^{[5,6]}$.

The rationale behind the prompt treatment of fracture neck of femur is "preservation of the blood supply" to the femoral head, which is key for a good long-term result. The fracture is considered a vascular injury to the femur head blood supply ${ }^{[7}$, ${ }^{8]}$. The degree of vascular compromise is directly proportional and correlates with the fracture displacement, which affects healing of the bone and leads to complications. Hence, intracapsular fracture neck of femur is considered an orthopaedic emergency ${ }^{[1]}$ and needs prompt adequate reduction with rigid internal fixation which improves the femoral head blood circulation and prevents the troublesome complications.

Internal fixation with cannulated cancellous (CC) screws after good reduction is the ideal method of treating femur neck fractures, as there is less blood loss, shorter operative time and less duration of hospital stay. Thus parallel screw fixation at present, considered as the standard with which other implants have to be compared ${ }^{[1]}$.

Therefore, we conducted this study in our institute to evaluate functional outcome of patients with neck of femur fracture treated with cannulated cancellous (CC) screws. We specially focused on the time lapse from injury to the surgery in relation to union and occurrence of complications such as non-union.

\section{Objectives of the Study}

- To assess the efficacy of cannulated cancellous screws in osteo-synthesis of femoral neck fractures.

- To determine the average time taken for union.

- To study the functional outcome of fracture neck of femur managed with cannulated cancellous (CC) screw fixation and assessing the results.

\section{Methodology}

- A prospective study on about 30 consecutive patients with fracture of femoral neck meeting the inclusion and the exclusion criteria admitted to RL Jalappa hospital attached to Sri Devaraj Urs Medical College and research centre were taken up for the study after obtaining the informed consent between the period of September 2016 to September 2018.

\section{Inclusion Criteria}

- Undisplaced (Garden type I and II) neck of femur fractures in all age groups.

- Displaced (Garden type III and IV) fractures in patients below 65 years of age.

\section{Exclusion Criteria}

- Osteoarthritis of hip joint

- Pathologic fracture

- Rheumatoid arthritis

- Patients with acetabulum fractures

- Ipsilateral shaft of femur fracture

- Fracture neck of femur with dislocation.

\section{Method of Collection of Data}

- It is a prospective study.

- Admitted patients were evaluated for fitness, routine pre anesthetic check-up was done and informed written consent was taken before surgery.
- The fractures were classified according to the Garden's classification based on radiological findings and fixed with 3 cannulated cancellous (cc) screws in an inverted triangle configuration.

\section{Post Operatively}

- $\quad$ Check x rays pelvis with both hips AP view and operated hip lateral view were done. The same radiographs were taken on subsequent follow-ups.

- Blood investigations: haemoglobin

- Patients were shifted to high dependency surgical ward and monitored.

- $\quad$ Check X-ray of pelvis and both hip in AP and operated hip in lateral views were done.

- Appropriate analgesics (Inj. Diclofenac or Inj. Tramadol) were given intramuscularly.

- IV antibiotics (Inj. Cefotaxime) was given for 2-3 days.

- IV fluids in high dependency ward as appropriate were given.

- $\quad$ Stitches were removed 2 weeks after surgery.

The patients were mobilized with strict non-weight bearing ambulation post-operatively with the help of a walker. They were discharged with a strict advice of non-weight bearing ambulation and to do active quadriceps exercises and were called for follow up after 4 weeks. On subsequent follow up, the next date of follow up was given.

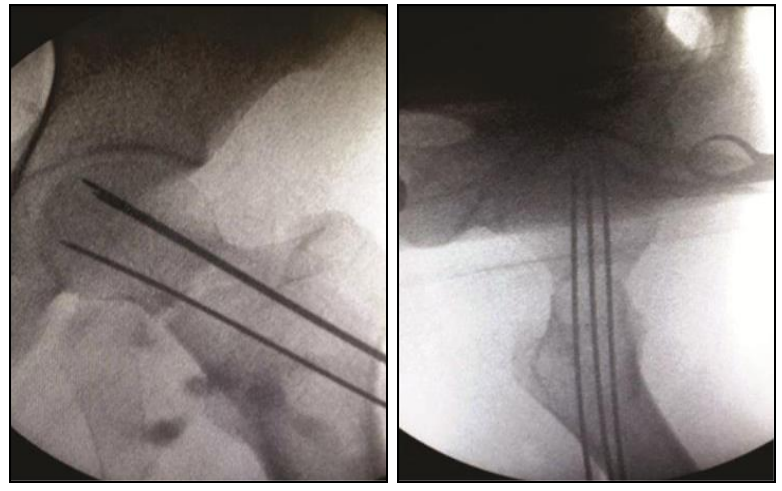

Fig 1: Guide-wire position confirmation under c-arm fluoroscopy
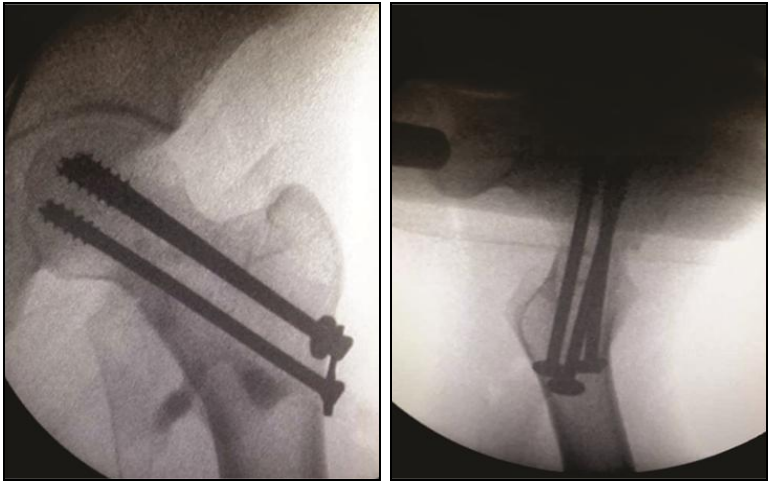

Fig 2: Final screw positions under c-arm fluoroscopy

\section{Follow Up}

- Follow up was done on $4^{\text {th }}, 8^{\text {th }}, 12^{\text {th }}, 16^{\text {th }}$ and $24^{\text {th }}$ weeks. At all follow ups, symptoms like pain or swelling were noted and a detailed clinical examination was done, and looked for tenderness, active range of movements of hip and limb length discrepancy. Subjective assessment of functional outcome was done using Modified Harris Hip Score at each follow up. 
- X-rays were repeated on $4^{\text {th }}, 12^{\text {th }}$ and $24^{\text {th }}$ weeks (ie. $1^{\text {st }}$, $3^{\text {rd }}$ and $5^{\text {th }}$ follow ups) and were observed for signs of union (trabecular continuity across fracture site), neckshaft angle, screw backing out or breaking of screws.

- Patients were advised non-weight bearing ambulation for first 8 weeks, followed by foot touch down (partial weight bearing) ambulation from $8^{\text {th }}-12^{\text {th }}$ week and full weight bearing after 12 weeks if radiographs showed signs of union.

\section{Results}

Following were the observations made and the available data were analyzed as follows.

\section{1) Age distribution}

In this study, majority of cases, $20(66 \%)$ were in $31-50$ years age group, followed by $5(17 \%)$ each in the age group of 1830 and above 50 . The youngest patient's age was 24 years and eldest was 65 years old. The mean age was 41.3 years

Table 1: Age distribution

\begin{tabular}{|c|c|c|c|c|}
\hline Age (in years) & $\mathbf{1 8 - 3 0}$ & $\mathbf{3 1 - 4 0}$ & $\mathbf{4 1 - 5 0}$ & $>\mathbf{5 0}$ \\
\hline No. of cases & 5 & 10 & 10 & 5 \\
\hline Percentage & 17 & 33 & 33 & 17 \\
\hline
\end{tabular}

\section{2) Sex distribution}

In our study, majority $21(70 \%)$ of cases were males, and females were $9(30 \%)$ cases, with Male: Female ratio of 3:1.

Table 2: Sex distribution

\begin{tabular}{|c|c|c|}
\hline Sex & No. of cases & Percentage \\
\hline Male & 21 & 70 \\
\hline Female & 9 & 30 \\
\hline
\end{tabular}

\section{3) Side involvement}

Right side was involved in $18(60 \%)$ cases and left side in $12(40 \%)$ cases.

Table 3: Side involvement

\begin{tabular}{|c|c|c|}
\hline Side & No. of cases & Percentage \\
\hline Right & 18 & 60 \\
\hline Left & 12 & 40 \\
\hline
\end{tabular}

\section{4) Mode of injury}

The most common mode of injury was road traffic accident. 21 cases $(70 \%)$ out of 30 cases were affected due to road traffic accident and rest 9 cases $(30 \%)$ were due to fall.

Table 4: Mode of injury

\begin{tabular}{|c|c|c|}
\hline Mode of injury & No. of cases & Percentage \\
\hline Road traffic accident (RTA) & 21 & 70 \\
\hline Fall & 9 & 30 \\
\hline
\end{tabular}

\section{5) Fracture type-Garden's classification}

In our study out of 30 cases, majority were Garden's type II$15(50 \%)$ cases followed by Type III, $8(26.66 \%)$ cases, Type IV, $8(13.33 \%)$ and Type I, 3(10\%) cases.

Table 5: Fracture type-Garden's classification

\begin{tabular}{|c|c|c|}
\hline Garden's classification & No. Of cases & Percentage \\
\hline I & 3 & 10 \\
\hline II & 15 & 50 \\
\hline III & 8 & 26.66 \\
\hline IV & 4 & 13.33 \\
\hline
\end{tabular}

\section{6) Time interval between injury and surgery}

In our study, $18(60 \%)$ cases were operated within 12 hours of trauma and 12(40\%) cases were operated within 12-48 hours.

Table 6: Time interval between injury and surgery

\begin{tabular}{|c|c|c|}
\hline Time elapsed & $<\mathbf{1 2}$ hours & $>\mathbf{1 2}$ hours \\
\hline No. of cases & 18 & 12 \\
\hline Percentage & 60 & 40 \\
\hline
\end{tabular}

\section{7) Time taken for union}

In our study, the average time taken for union was 15 weeks. Most of the cases showed union in 12 weeks, 17 patients followed by 16 weeks in 7 patients and 24 weeks, 6 cases.

Table 7: Time taken for union

\begin{tabular}{|c|c|c|c|}
\hline Union (weeks) & Twelve & Sixteen & Twenty four \\
\hline No. of cases & 17 & 7 & 6 \\
\hline
\end{tabular}

\section{8) Complications}

In our study, 6(20\%) cases had complications. The most common complication were superficial infection and backing out of screws, 4 cases $(13.33 \%)$. There were no implant failure or non-union.

Table 8: Complications

\begin{tabular}{|c|c|c|}
\hline Complications & No. of cases & Percentage \\
\hline Superficial infection & 4 & 13.33 \\
\hline Backing out of screw & 4 & 13.33 \\
\hline Restricted movements & 3 & 10 \\
\hline
\end{tabular}

\section{9) Results-According to Modified Harris Hip score}

In the present study, 30 patients with fracture neck of femur were treated surgically. The results were satisfactory in 93.33\% cases by the subjective Modified Harris Hip scoring system. The functional outcome was Excellent in 22 cases (73.33\%), Good in 6 cases (20\%) and in 2 cases (6.66\%) Fair. Excellent results were observed equally irrespective of timing of surgery in our study i.e within 2 days. No patient had a poor outcome at their final follow up.

Table 9: Results-According to Modified Harris Hip score

\begin{tabular}{|c|c|c|}
\hline Results & No of cases & Percentage \\
\hline Excellent & 22 & 73.33 \\
\hline Good & 6 & 20 \\
\hline Fair & 2 & 6.66 \\
\hline Poor & 0 & 0 \\
\hline
\end{tabular}

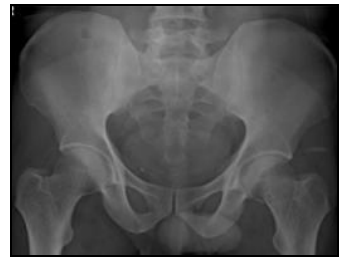

Pre op X-ray (AP View)

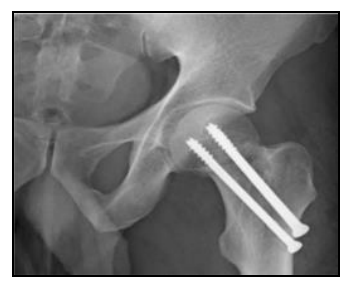

Post op x-ray

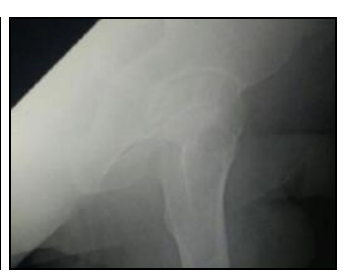

Pre op X-ray (Lateral)

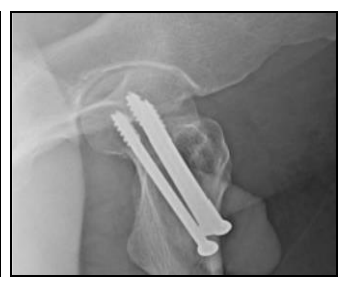

Post op x-ray 


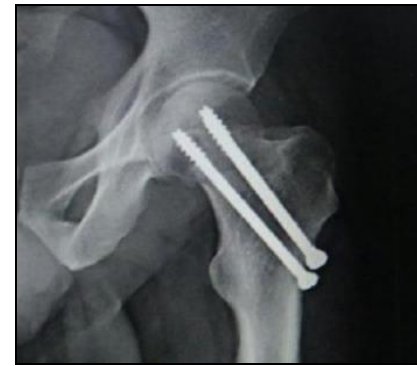

3 months follow up

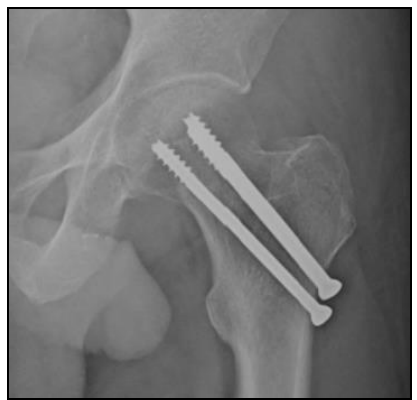

6 months follow up
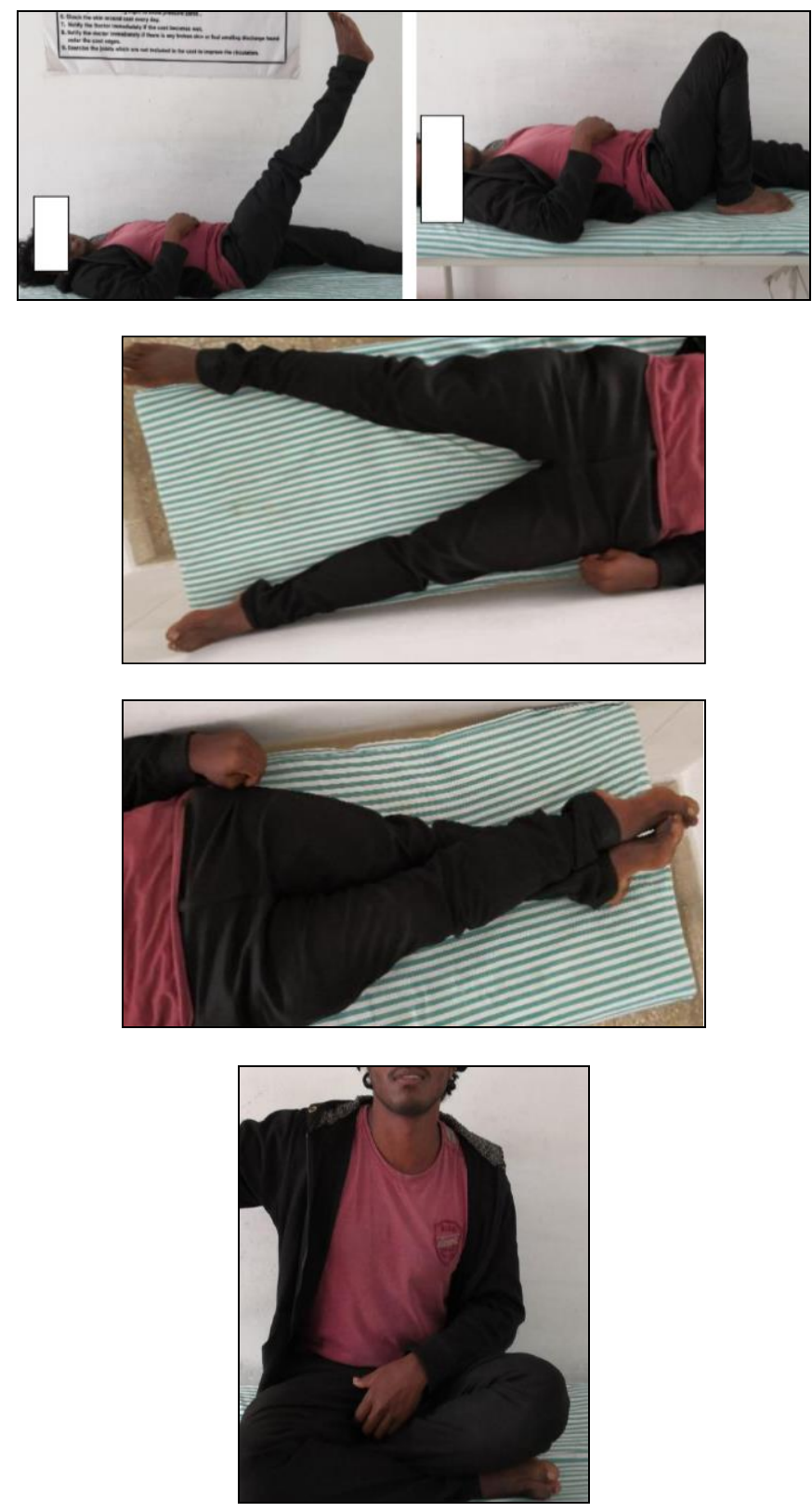

Fig 3: Clinical follow up range of motion photograph

\section{Discussion}

The femoral neck fracture is the most common skeletal injury, occurring with minor trauma in the osteoporotic bone of elderly patients. In younger patients, usually with a high energy trauma.

The management of this fracture has evolved significantly

- Closed reduction and immobilization in POP hip spica in abduction and internal rotation (Whitman abduction plaster) in the early part of $20^{\text {th }}$ century $[9,10]$. High incidence of non-union, AVN, bedsores and respiratory complications led to exploration of methods of internal fixation.

- The introduction of SP Nail brought a new aspiration of solving the problem, but high failure and complication rates disappointed many surgeons.

- Further improvement in implant designs brought a newer designs like SP nail plate and McLaughlin nail plate which did not the withstand the test of time.

- The modern concepts of fixation under compression led to the use of partially threaded cancellous screws and placement over preliminary wires led to the development of cannulated variety of screws, which are now the standard of care in adults. Smooth pins (Moore or Knowles pins) are still the choice for children.

The presentation at different ages possess different problems related to the management. The issues are fixation failure in osteopenic bone of the elderly, marked displacement of fragments, posterior comminution and disruption of blood supply in young adults and a higher incidence of AVN and non-union young adults.

The blood supply to the femoral head is derived from from primarily from three sources, medial femoral circumflex artery and lateral femoral circumflex artery through the extracapsular arterial ring formed at the base of neck of femur and subsequently through intracapsular terminal branches which run parallel to the neck and obturator artery via the artery of ligamentum teres. A femur neck fracture is considered a vascular injury to the femoral head as it disrupts the terminal vessels (the retinacular arteries) which lie in close conjunction to the femoral neck. It is an intracapsular fracture which exposes it to synovial fluid which had factors neovascularization. Moreover due to action of theses surrounding musculature and fracture pattern a high degree of sheering strain is subjected to it. Hence, proper anatomical reduction and secure internal fixation are of paramount importance in its treatment.

The treatment of fracture neck of femur with anatomical reduction, early and stable fracture fixation using cannulated screws has been found to give a high proportion of excellent and good results ${ }^{[6,8,11]}$. This study supports these conclusions.

\section{Statistic Results of Surgery}

- Most of the cases $(70 \%)$ were operated in the first 12 hours.

- All the cases were operated under spinal anaesthesia.

- On an average the duration of surgery was one hour.

1) Age Distribution: In our study fractures were commoner (55\%) in the 31-50 age group with mean age being 41.3 years. The findings in our stuidy are comparable to those in a study by Christopher Koo Chee Han et al. ${ }^{[40]}$. 
Table 10: Age distribution comparison

\begin{tabular}{|c|c|c|}
\hline Study & No. of cases & $\begin{array}{l}\text { Mean age } \\
\text { (in years) }\end{array}$ \\
\hline Vijay V et al. ${ }^{[12]}$ & 25 & $50(20-90)$ \\
\hline Dincel Y M et al. ${ }^{[13]}$ & 67 & $46.5(18-75)$ \\
\hline Christopher Koo Chee Han et al. ${ }^{[11]}$ & 53 & $42.1(6-91)$ \\
\hline Present study & 30 & $41.3(24-65)$ \\
\hline
\end{tabular}

2) Sex Distribution: Our series had a male predominance with $70 \%$ and male: female ratio of 2.33:1. The findings are comparable to the studies by Christopher Koo Chee Han et al. and Vijay V. The male preponderance in our series can be accredited to the cause of fracture mainly being RTA.

Table 11: Sex distribution comparison

\begin{tabular}{|c|c|c|}
\hline Study & $\begin{array}{c}\text { No. of male: } \\
\text { female }\end{array}$ & $\begin{array}{c}\text { Male: } \\
\text { Female }\end{array}$ \\
\hline Vijay V et al. $^{[12]}$ & $30: 34$ & $2.57: 1$ \\
\hline Dincel Y M et al. $^{[13]}$ & $39: 28$ & $1.3: 1$ \\
\hline${\text { Christopher Koo Chee Han } \text { et al. }^{[11]}}^{11}$ & $39: 14$ & $2.7: 1$ \\
\hline Present study & $21: 9$ & $2.33: 1$ \\
\hline
\end{tabular}

3) Garden's Type of Fracture: In our study, Garden's classification system was used for operative evaluation. The most common type of injury was type II, 15 cases (50\%) followed by type III, 8 cases $(26.66 \%)$.

Table 12: Fracture type comparison

\begin{tabular}{|c|c|c|}
\hline Study & $\begin{array}{c}\text { Garden type } \\
\text { I \& II }\end{array}$ & $\begin{array}{c}\text { Garden type } \\
\text { III \& IV }\end{array}$ \\
\hline Vijay V et al. ${ }^{[12]}$. & 11 & $14(56 \%)$ \\
\hline Dincel Y M et al. ${ }^{[13]}$. & $30(44.7)$ & $37(55.3)$ \\
\hline Christopher Koo Chee Han et al. ${ }^{[11]}$. & $17(32.1)$ & $36(67.9)$ \\
\hline Present study & $18(60)$ & $12(40)$ \\
\hline
\end{tabular}

4) Functional Results: The functional results in our study were calculated using the Modified Harris Hip Score. The score was calculated at each follow-up and the functional result was based on the score at the final follow-up. The functional results of the present study were comparable with that of Vijay V et al. with $73.33 \%$ excellent results, $20 \%$ having good results and fair results in $6.66 \%$.

Table 13: Functional results comparison

\begin{tabular}{|c|c|c|c|c|}
\hline Study & $\begin{array}{c}\text { Excellent } \\
(\mathbf{\%})\end{array}$ & $\begin{array}{c}\text { Good } \\
(\mathbf{\%})\end{array}$ & $\begin{array}{c}\text { Fair } \\
(\mathbf{\%})\end{array}$ & $\begin{array}{c}\text { Poor } \\
(\mathbf{\%})\end{array}$ \\
\hline Vijay V $^{[12]}$. & $18(72)$ & $4(16)$ & $2(8)$ & $1(4)$ \\
\hline $\begin{array}{c}\text { Christopher Koo Chee Han } \text { et al. } \\
{[11] .}\end{array}$ & $41(93.2)$ & 0 & $2(4.5)$ & $1(2.27)$ \\
\hline Present study & $22(73.33)$ & $6(20)$ & $2(6.66)$ & 0 \\
\hline
\end{tabular}

5) Union Duration and Rate: In our study, the average time taken for union was 15 weeks. Most of the case showed union in 12 weeks (17 patients). No patient had non-union. The findings of the present study were comparable with that of Christopher Koo Chee Han et al.

Table 14: Union duration and rate comparison

\begin{tabular}{|c|c|c|c|}
\hline Study & Weeks & $\begin{array}{c}\text { No. of } \\
\text { union (\%) }\end{array}$ & $\begin{array}{c}\text { Non } \\
\text { union }\end{array}$ \\
\hline Vijay V et al. ${ }^{[12]}$. & - & $24(96)$ & 1 \\
\hline Dincel Y M et al. ${ }^{[13]}$. & 24 & $64(95.52)$ & $3(4.47)$ \\
\hline Christopher Koo Chee Han et al. ${ }^{[11]}$. & 14.96 & $52(98.11)$ & $1(1.89)$ \\
\hline Present study & 15 & $30(100 \%)$ & Nil \\
\hline
\end{tabular}

6) Time Interval Between Injury and Surgery

In our study, most of the cases were operated within the first 12 hours of the trauma, 18 cases $(60 \%)$.

Table 15: Time elapsed between trauma and surgery comparison

\begin{tabular}{|c|c|c|}
\hline Study & \multicolumn{12}{|c|}{ hours (\%) } & 12 hours (\%) \\
\hline Vijay V et al. ${ }^{[12]}$ & Nil & $25(100)$ \\
\hline Dincel Y M et al. ${ }^{[13]}$ & $67(100)$ & Nil \\
\hline Christopher Koo Chee Han et al. $^{[11]}$ & $25(47.17)$ & $28(52.83)$ \\
\hline Present study & $18(60)$ & $12(40)$ \\
\hline
\end{tabular}

7) Complications: The complications seen were superficial infection, restricted movements and backing out of screws. In our study further follow up is necessary to evaluate the incidence of AVN. All patients were able to carry out their daily activity with minimal or no discomfort. $4(13.33 \%)$ patients in our study had screw back-out and superficial infections.

Preservation of the femoral head with internal fixation is desirable in younger and more active patients with a femoral neck fracture. A healed femoral neck fracture, without the development of osteonecrosis, leads to a good functional outcome ${ }^{[11]}$. Eventual good outcomes after fixation are dependent on:

- The factors under surgeon's control such as quality of reduction, stable fixation and timing of surgery

- Factors not under surgeon's control such as initial fracture displacement and disruption of femur head blood flow and patients presenting late ${ }^{[14]}$.

Swiontkowski ${ }^{[6,8]}$ stated that early fixation, ideal reduction the most important factors for successful surgery, and should be done in $12 \mathrm{~h}$. In our study, most of the fractures $(60 \%)$ were fixed within 12 hours and the final results in all but one case were excellent. The other case had a good result at last follow up.

Jain et al. ${ }^{[5]}$, in their study compared the functional outcome of femur neck internal fixation within 12 hours and after 12 hours in patients under 60 years of age over a follow up period of 2 years and they did not find any significant difference in the outcome. Our study confirmed the same as there was no difference in the outcome of patients operated early ( $<12$ hours) and late ( $>12$ hours). Functional results are similar in both groups.

Placement of the screw is also of paramount importance. Inverted triangle with apex inferior is preferred as there will be less stress raiser affect and decreases the subsequent chances of subtrochanteric fracture. The screws should be placed as far as possible from one another close to the cortical bone of femoral neck. Screws should be parallel with unacceptation of not more than 10 degree angulation between them. Screws tips should be within $5 \mathrm{~mm}$ of subchondral bone ${ }^{[15]}$. In our study early non-weight bearing ambulation was allowed with the help of a walker strictly for 8 weeks. Partial weight bearing was allowed following 8 weeks and full weight bearing was allowed once radiological signs of union were seen. The normal hip range of motion was restored in almost all cases.

The superior rate of fracture healing in the study was attributed to the good bone quality and healing potential of the femoral head and neck of most young patients and due to early fracture fixation.

The limitations of our study include small size of the study group, short follow up which was not enough to evaluate and 
comment on the incidence of AVN. The study require further follow up to comment on incidence of AVN.

The treatment of fracture neck of femur in adults with anatomical closed reduction stable internal fixation using cannulated cancellous screw was found to give a satisfactory proportion of excellent and good results ${ }^{6,8,11}$. This study supports these conclusions and the results were comparable with those in the other studies.

\section{Conclusion}

In the study, 30 cases of fracture neck of femur were treated surgically by closed reduction and internal fixation with cannulated cancellous screws. In conclusion, fracture neck of femur in young adults treated surgically by closed reduction and fixation with cannulated cancellous screw fixation gave excellent to good functional outcome in $93.33 \%$. Hence this would be the best procedure for management of fracture neck of femur in adults under 65 years of age even for displaced fractures and the review of data and our study all point to the fixation of fracture as early as possible to avoid poor results.

\section{References}

1. Keating JF. Femoral neck fractures. In: Court-Brown CM, Heckman JD, McQueen MM, Ricci WM, Tornetta III P. Rockwood and Green's Fractures in adults $8^{\text {th }}$ ed. Philadelphia: Lippincott Williams \& Wilkins, 2015, 2031-73.

2. Weinlein JC. Fractures and dislocations of the hip. In: Azar FM, Beaty JH, Canale ST. Campbell's operative orthopedics $13^{\text {th }}$ ed. Philadelphia: Mosby Elsevier, 2018, 2817-57.

3. Lee KBL, Howe TS, Chang HC. Cancellous screw fixation for femoral neck fracture: one hundred and sixteen patients. Ann Acad Med Singapore. 2004; 33:248-51.

4. Rai SK et al. Fracture neck of femur treated with hemiarthroplasty and cannulated cancellous screw fixation: a comparative study. Int J Res Orthop. 2017; 3(4):849-53.

5. Jain R, Koo M, Kreder HJ, Schemitsch EH, Davey JR, Mahomed NN. Comparison of early and delayed fixation of subcapital hip fractures in patients sixty years of age or less. J Bone Joint Surg Am. 2002; 84:1605-12.

6. Thuan VL, Swiontkowski MF. Treatment of Femoral Neck fractures in Young Adults. J Bone Joint Surg Am. 2008; 90:2254-66.

7. Protzman RR, Burkhalter WE. Femoral neck fractures in young adults. J Bone joint Surg Am. 1976; 58: 689-95.

8. Swiontkowski MF, Winquist RA, Hansen ST. Fractures of femoral neck in patients between ages of twelve and forty nine years. J Bone Joint Surg Am. 1984; 66:837-46.

9. Whitman R. A new method of treatment for fractures of the neck of the femur, together with remarks on coxa vara. Ann Surg. 1902; 36(5):746-61.

10. Whitman R. The abduction method considered as the standard routine in the treatment of fractures of the neck of femur. Ann Surg. 1920; 81(1):374-91.

11. Khoo CCH, Haseeb A, Singh VA. Cannulated Screw Fixation For Femoral Neck Fractures: A 5-year Experience in a Single Institution. Malays Orthop J. 2014; 8(2):14-21.

12. Vijay V, Srivastava N. Cannulated cancellous screws fixation in intracapsular fracture neck femur: a study with an emphasis on result of osteosynthesis Int J Res Orthop. 2016; 2(3):181-8.
13. Dinçel YM, Öner A, Arıkan Y, Özkul B, Özcafer R, Güleç MA. Closed reduction and fixation of high-energy femoral neck fractures: Still a viable surgical treatment option. Biomed Res. 2017; 28(20):9028-31.

14. Szita J, Fekete K. Intracapsular femoral neck fractures: the importance of early reduction and stable osteosynthesis. Injury. 2002; 33(3):C41-6.

15. Forsh DA, Ferguson TA. Contemporary management of femoral neck fractures: the young and the old. Curr Rev Musculoskelet Med. 2012; 5(3):214-21. 